\title{
Epidrugs: novel epigenetic regulators that open a new window for targeting osteoblast differentiation
}

\author{
Mahsa Ghorbaninejad ${ }^{1,2,3+}$, Maliheh Khademi-Shirvan ${ }^{2,3+}$, Samaneh Hosseini ${ }^{2,4^{*}}$ \\ and Mohamadreza Baghaban Eslaminejad ${ }^{2^{*}}$
}

\begin{abstract}
Efficient osteogenic differentiation of mesenchymal stem cells (MSCs) is a critical step in the treatment of bone defects and skeletal disorders, which present challenges for cell-based therapy and regenerative medicine. Thus, it is necessary to understand the regulatory agents involved in osteogenesis. Epigenetic mechanisms are considered to be the primary mediators that regulate gene expression during MSC differentiation. In recent years, epigenetic enzyme inhibitors have been used as epidrugs in cancer therapy. A number of studies mentioned the role of epigenetic inhibitors in the regulation of gene expression patterns related to osteogenic differentiation. This review attempts to provide an overview of the key regulatory agents of osteogenesis: transcription factors, signaling pathways, and, especially, epigenetic mechanisms. In addition, we propose to introduce epigenetic enzyme inhibitors (epidrugs) and their applications as future therapeutic approaches for bone defect regeneration.
\end{abstract}

Keywords: Epigenetic, Epidrug, Mesenchymal stem cell, Osteoblast

\section{Background}

Mesenchymal stem cells (MSCs) are considered to be potent tools for regenerative medicine, tissue engineering, and cellbased therapy because of their tri-lineage differentiation, selfrenewal potential, low immunogenicity, decreased risk for tumorigenicity, capability for expansion, and ease of accessibility [1]. During bone homeostasis and bone fracture repair, MSCs differentiate into osteoblasts that ultimately result in bone formation and regeneration. However, the application of MSCs in cell-based therapy may present challenges, such as unexpected differentiation of MSCs in different in vivo situations and low survival of MSCs after transplantation.

\footnotetext{
* Correspondence: hosseini.samaneh@royaninstitute.org;

eslami@royaninstitute.org

${ }^{\dagger}$ Mahsa Ghorbaninejad and Maliheh Khademi-Shirvan contributed equally to this work

${ }^{2}$ Department of Stem Cells and Developmental Biology, Cell Science Research Center, Royan Institute for Stem Cell Biology and Technology, ACECR, Tehran, Iran

Full list of author information is available at the end of the article
}

Thus, it is necessary to have a better understanding of the osteogenesis process and its exact regulatory mechanism [2, 3]. The process of osteogenic differentiation of MSCs is largely controlled by successive changes in the pattern of gene expression related to osteogenesis. Osteoblast differentiation of MSCs is highly modulated by cross-talk between genes, transcription factors, signaling pathways, and epigenetic mechanisms [4]. Epigenetic modulators alter chromatin architecture and change accessibility of genes to transcription factors and other regulators. These changes are largely responsible for the up- and downregulation of specific genes during a cell's lifespan [5]. Disruption of epigenetic regulation is associated with human diseases, including those responsible for abnormalities in development, cancer, and neuropsychiatric disorders. Hence, an epigenetic study of the gene expressions involved in the osteogenic differentiation pathway would be beneficial in order to understand the process of osteogenesis. Major epigenetic mechanisms 
include DNA methylation, histone modifications, chromatin remodeling, and miRNA [6]. One attractive strategy that can target epigenetic change is the application of chemical modifiers as epigenetic enzyme inhibitors, termed epidrugs. These epidrugs may represent a step forward in cancer therapy and treatment of other diseases in which epigenetic regulation plays a key role [7]. The effects of epidrugs have been confirmed in relevant biological models. Several chemical modifiers have been studied in the induction of epigenetic regulation in MSC differentiation toward the osteoblast lineage [8]. In this article, we review the genes, transcription factors, signaling pathways, and, particularly, epigenetic mechanisms that govern the osteogenic process. We discuss the role of epigenetic changes and their modifiers as one of the most promising and expanding fields in MSC differentiation. Finally, the impact of epidrugs as attractive candidates for the regulation of epigenetic mechanisms in osteoblast differentiation of MSCs is discussed.

\section{Regulation of osteogenesis by genes and signaling pathways}

Osteoblastogenesis has three important phases that are characterized by sequential expression of specific osteoblastic markers: proliferation, matrix maturation, and mineralization. Major genes involved in the osteoblast differentiation process include alkaline phosphatase (ALP), type 1 collagen (COL1A1), osteopontin (OPN), bone sialoprotein (BSP), and osteocalcin (OCN) [9]. ALP, BSP, and COL1A1 are typically expressed during the early stage of osteoblast differentiation, while $\mathrm{OCN}$ is expressed during the late stage and is associated with mineralization. Runtrelated transcription factor 2 (Runx2) and osterix (Osx) are two important transcription factors that promote osteoblastogenesis [10].

Runx2, the most important transcription factor, is essential for bone formation and activation of osteogenic genes [11]. Runx2 acts as a master regulator upstream of the genes and transcription factors that are involved in osteogenesis. It binds to a specific site of the OCN, COL1A1, ALP, and OPN gene promoters [12]. Runx2 also regulates Osx expression, another major transcription factor for osteogenic differentiation [13]. Similarly, Osx, known as Sp7, is expressed by osteoblasts. Osx is essential for bone formation. Osx activates COL1A1 by interaction with its promoter [14, 15].

In addition to specific genes in the osteogenesis process, there are several known signaling pathways that play critical roles during osteoblast differentiation. MSCs proliferate and differentiate in response to these signaling pathways during different stages of osteogenesis. Activation of specific genes mediated by molecular signaling pathways regulates MSC differentiation [16].
Hedgehog (Hh), Notch, Wnt, parathyroid hormone $(\mathrm{PTH})$, fibroblast growth factor (FGF), and the transforming growth factor- $\beta$ (TGF- $\beta$ ) super family signaling are the most well-known signaling pathway regulators of osteogenesis.

Hh, an important secreted molecule of the hedgehog family, regulates cell functions during bone formation. The Hh receptor is expressed on the surface of osteoblasts. Shh, Ihh, and Dhh are members of the Hh family in mammals, and Shh and Ihh are vital for bone development. Family members of the Hh protein bind to its receptor, Ptc, which inhibits Smo, a key transducer in Hh signaling, and leads to activation of the GLI family (Gli1-3) transcription factors. Gli translocate into the nucleus and activate a series of Hh target genes (Fig. 1a). Results of studies based on rodent mesenchymal cell lines have demonstrated that $\mathrm{Hh}$ increased the expression of osteoblastic markers and mineralization [17].

In addition, Notch signaling has a key role in cellular development and tissue morphogenesis. Notch signaling requires cell-cell interaction between Notch receptors and Delta or Jagged family ligands present on the surface of the neighboring cells. Notch receptors activate by binding with ligands, which results in cleavage by ADAM/TACE metalloprotease, followed by cleavage with $\gamma$-secretase. This leads to release and nuclear translocation of NICD, where NICD interacts with the CSL family transcription factor and MAML co-activator. This complex targets HES and the HEY family of transcription factors, which control the expressions of other genes such as Runx2 (Fig. 1b). Conflicting results have been reported in terms of Notch signaling and regulation of osteoblast differentiation. Activation of Notch during the early stages of osteogenesis suppresses differentiation of osteoblasts from osteoprogenitors, while activation in the late stages exerts anabolic effects and causes excessive production of osteocytes from osteoblasts, resulting in bone formation [18]. Wnt signaling is another signaling pathway in development and skeletal pattern. Canonical Wnt signaling is activated by the Wnt1/3a protein when it binds to the G protein-coupled receptor and co-receptors at the cell surface, named FZD, and the low-density LRP5 or LRP6 complex. In the absence of Wnt, $\beta$-catenin is phosphorylated by a complex that contains GSK3. The ligand-receptor complexes inhibit GSK3, which prevents $\beta$-catenin degradation. $\beta$ catenin accumulates in the cytosol and translocates in the nucleus to regulate target gene transcription. In the Wnt-PCP pathway, Wnt binding to FZD activates Rho/ Rack GTPase and the JNK signaling cascade (Fig. 1c). Wnt proteins regulate a wide range of cellular activities, including growth, cell fate determination, polarity, differentiation, migration, and proliferation [19]. 


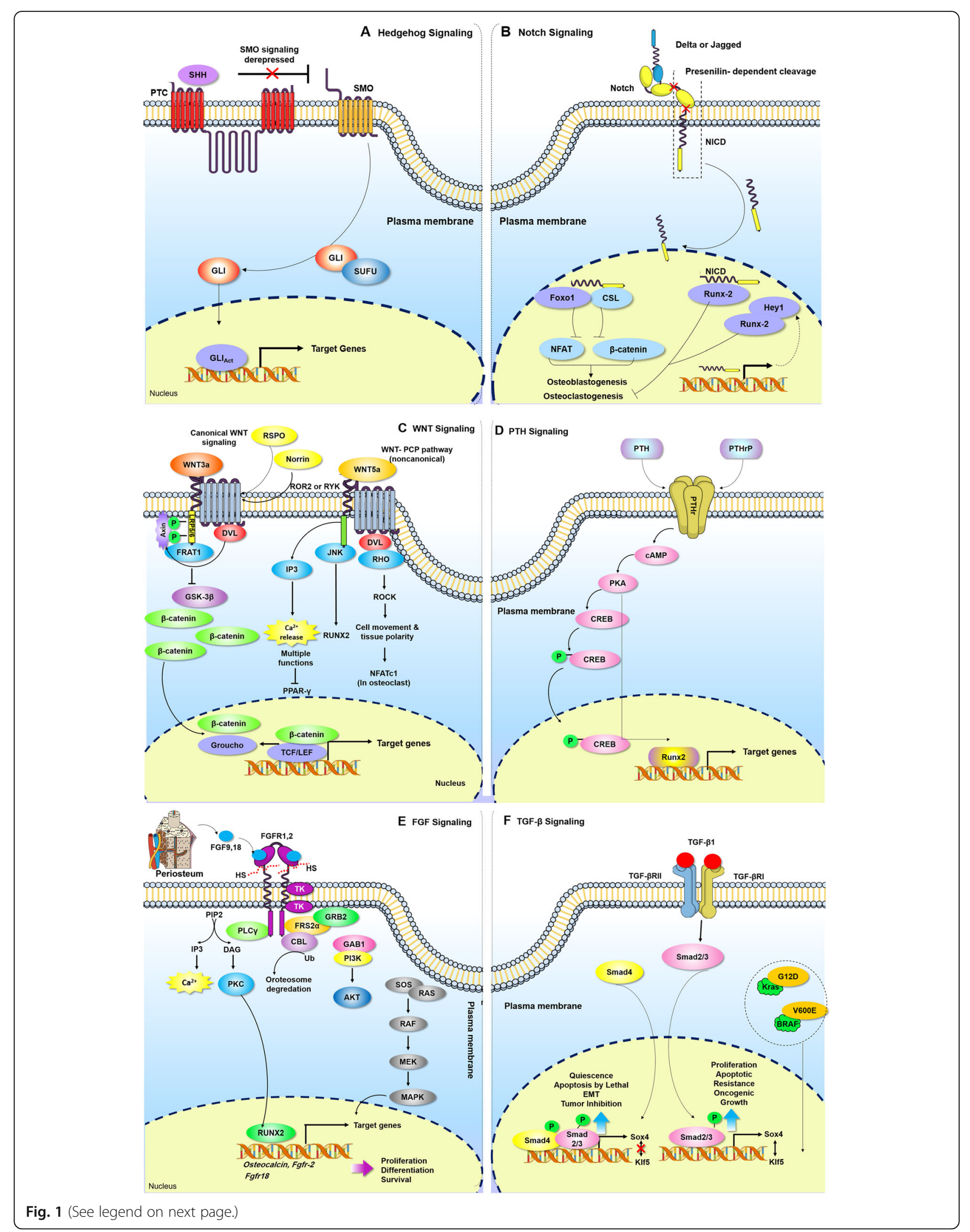


(See figure on previous page.)

Fig. 1 Osteogenesis regulating signaling pathways. a Hedgehog signaling pathway: Hh, an important secreted molecule of the hedgehog family, regulates cell functions during bone formation. Hh, hedgehog; Shh, Sonic hedgehog; Ihh, Indian hedgehog, Dhh; Desert hedgehog; Ptc, patched; Smo, smoothened. b Notch signaling pathway: Notch signaling has a key role in cellular development and tissue morphogenesis. Runx2, runtrelated transcription factor 2; ADAM, a disintegrin and metalloprotease; TACE, tumor necrosis factor-a converting enzyme; NICD, Notch intracellular domain; CSL, C protein binding factor 1/suppressor of Hairless/Lag-1; MAML, mastermind-like, HES, hairy and enhancer of split; HEY, HES-related with YRPW motif. c Wnt signaling pathway: Wnt signaling is another signaling pathway in development and skeletal pattern. The noncanonical signaling pathway plays a role in regulating the osteoblast lineage. FZD, frizzled; LRP5 or LRP6, lipoprotein receptor-related protein 5 or 6; GSK3, glycogen synthase kinase 3; JNK, c-Jun N-terminal kinase. d PTH/ PTHrP signaling pathway: PTH may have either catabolic or anabolic effects on bone formation, depending on its route of administration. PTH, parathyroid hormone; PTHrP, PTH-related peptide; PTHR, PTH/ PTHrP receptor; PKA, protein kinase A; CREB, CAMP response element binding protein. e FGF signaling pathway: FGF signaling plays an important role during skeletal development and it controls endochondral and intramembranous ossification. FGF, fibroblast growth factor. $\mathbf{f}$ TGF- $\beta / B M P$ signaling: TGF- $\beta$ and BMP signaling are of utmost importance in both bone formation during skeletal development and maintenance of postnatal bone. TGF- $\beta$, transforming growth factor- $\beta$; BMPs, bone morphogenetic proteins; R-Smad, receptor-regulated Smad; co-Smad,

common-mediator Smad

Binding of PTH and PTHrP to PTHR leads to activation of the cAMP/protein kinase A (PKA) signaling pathway. Subsequently, PKA phosphorylates CREB, which regulates transcription of PTH target genes during osteogenesis (Fig. 1d). PTH may have either catabolic or anabolic effects on bone formation, depending on its route of administration. Continuous exposure of PTH results in bone resorption by activation of osteoclasts [20], whereas intermittent subcutaneous infusions lead to bone augmentation [21]. FGF signaling plays an important role during skeletal development, and it controls endochondral and intramembranous ossification [22]. Following ligand-receptor binding, intrinsic tyrosine residues of FGFR undergo dimerization and phosphorylation and, in turn, activate several signaling pathways such as MAP/ERK, PLC $/ \mathrm{PKC} \alpha$, and PI3KAKT (Fig. 1e) [22]. According to the literature, FGF2 and FGF18 are the most important regulators in promoting osteogenic differentiation, and they can enhance stabilization and expression of Runx2 [23].

The TGF- $\beta$ superfamily consists of over 40 members, including TGF- $\beta$ s, Activins, Nodal, bone morphogenetic proteins (BMPs), and growth differentiation factors (GDFs). TGF- $\beta$ and BMP signaling are of utmost importance in both bone formation during skeletal development and maintenance of postnatal bone [24]. BMP family members are secreted by most skeletal cell types such as osteoprogenitor cells, osteoblasts, and bone extracellular matrix [25]. TGF- $\beta$ is a multifunctional growth factor that has a complex role in bone remodeling. Although three isoforms of TGF- $\beta(\beta 1-\beta 3)$ are synthesized by the majority of cells, platelets, endothelial cells, bone, and cartilage are the main sources of TGF- $\beta$ [26]. In the Smad-dependent signaling pathway, BMP/ TGF- $\beta$ bind to their specific type II receptor, which recruits and phosphorylates a type I receptor. The type I receptor then phosphorylates and activates R-Smads. Smad1, Smad5, and Smad8 are BMP activated, whereas Smad 2 and 3 are TGF- $\beta$ activated. R-Smads form a complex with co-Smad (Smad 4) and enter the nucleus to regulate transcription of target genes. BMPs can also transduce signals to Smad-independent signaling pathways, notably via MAP kinases (Fig. 1f). Of note, all of the mentioned signaling pathways interact with each other to modulate osteogenesis [27-31].

The interplay of molecular signals and genes enables MSCs to begin the differentiation process. The role of epigenetic modification in precise control of specific transcriptional programs and signaling pathways in the osteogenesis process has been less explored.

\section{Regulation of osteogenic differentiation by epigenetic mechanisms}

Epigenetics are heritable changes in the patterns of gene expression that do not directly alter DNA nucleotide sequences. Epigenetic marks include DNA methylation, histone modifications, microRNA (miRNA), and chromatin remodeling in diverse biological processes. The results from a growing number of studies have indicated that these mechanisms participate in all aspects of osteogenesis [32]. Below, we provide a detailed description of epigenetic marks and their impact on osteogenesis.

\section{DNA methylation}

DNA methylation is an epigenetic process that causes changes to chromatin that are associated with gene repression. In DNA methylation, a methyl group is added to the $5^{\prime}$ position of cytosine in a CpG dinucleotide [33]. Methylation is mediated by a number of DNA methyl transferases (DNMT) that consist of maintenance enzyme DNMT1 and de novo methyl transferases DNMT3A/3B. Methylation of DNA can be removed by demethylases, which include GADD45A, the TET family, and OCT4 [34].

DNA methylation associated with transcriptional silencing participates in biological processes such as imprinting of specific genes, $\mathrm{X}$ chromosome inactivation, and cell type-specific gene expressions [35]. According to 
numerous researches, DNA methylation plays a key role in osteogenesis of MSCs [36]. Delgado-Calle et al. have shown that an alteration in ALP gene expression was regulated by DNA methylation of its promoter region during osteogenesis in such a way that hypomethylation of the ALP promoter region in osteoblasts resulted in upregulation of the ALP gene. In contrast, reduced ALP expression in mature osteocytes resulted from hypermethylation of its promoter [37, 38]. Sepulveda et al. reported that DNA methylation processes control Sp7 gene expression during osteogenesis. They found that Sp7 gene silencing was mediated by DNMT1/3a. In contrast, activation of the $\mathrm{Sp} 7$ gene accompanied by DNA demethylation was mediated by SWI/SNF- and Tet1/ Tet2-containing complexes [39]. Wakitani et al. reported that DNA methylation in a new genomic region was related to Runx2 expression; methylation of Runx2-DMR decreased during osteogenic differentiation in mice and canines [40]. Hypomethylation in promoters of other specific osteogenic genes, such as ROR2, Dlx5, Runx2, $\mathrm{OCN}$, and Osx, occurs during osteogenic differentiation and results in increased mRNA expression [41, 42]. A recent study mentioned the pivotal role of DNA demethylases in the maintenance of MSCs and bone homeostasis. The results indicated that demethylases TET1 and TET2, through demethylation of the P2rX7 promoter and exosome releasing control, promote Runx2 signaling such that deletion of Tet 1 and Tet2 in a mouse model led to an osteoporotic phenotype and impaired BMMSC differentiation [43]. These findings indicate that DNA methylation regulates gene expression during osteogenesis in a time-dependent manner.

\section{Histone modifications}

Histone modifications are covalent post-translational modifications on the histone proteins. These modifications change the architecture of chromatin, which generally occurs at chemically unstable residues (i.e., lysine, arginine, serine, threonine, tyrosine, and histidine) on the histone tail regions. Histone tails are modified by acetylation, methylation, ubiquitination, phosphorylation, sumoylation, and ADP-ribosylation [44, 45]. Among these, most studies have focused on the role of histone acetylation and methylation during osteogenesis.

Histone acetylation is mediated by two classes of enzymes, histone acetyltransferases (HATs) and histone deacetylases (HDACs). Acetylation of lysine residues on histones neutralizes the partial electric charge of lysine, which relaxes the chromatin structure that correlates with transcriptional activation. In contrast, histone deacetylation compacts the chromatin structure and induces transcriptional repression [46].

Many studies have reported that histone acetylation regulates expression of osteo-specific genes. According to Shen et al., $\mathrm{H} 3$ and $\mathrm{H} 4$ acetylation was associated with fluctuations of OCN gene expression during osteogenesis. In the proliferative phase, acetylation of $\mathrm{H} 3$ and $\mathrm{H} 4$ decreased, which resulted in inactivation of OCN. In contrast, OCN was active in mature osteoblasts with increasing H4 acetylation [4]. Subsequently, Tan et al. performed ChIP-on-chip analysis on the full human genome promoter to study the role of histone modification during osteogenic differentiation of MSCs. Their findings revealed that H3K9Ac decreased while H3K9Me2 increased globally at the gene promoters during MSC osteogenic differentiation [47]. Another study reported that $\mathrm{p} 300 / \mathrm{CBP}$-associated factor (PCAF), an HAT, was required for osteogenic differentiation. PCAF, via histone acetylation of Runx2, promotes osteoblast differentiation. PCAF stimulates $\mathrm{H} 3 \mathrm{~K} 9$ acetylation at the promoters of the BMP signaling genes that control osteogenesis [48]. The Runx2/P57 P1 promoter region was accompanied by enhancement of activating histone marks, H3ac and H3K27ac, during osteogenesis of Wharton's Jelly MSCs (WJ-MSCs) [49]. In addition to HATs, HDACs are widely involved in osteogenic differentiation of MSCs. Gordon et al. have reported downregulation of HDAC1, HDAC2, and HDAC3 during osteogenesis [50]. A study by Simic et al. showed that Sirtuin 1 (SIRT1), an HDAC, deacetylated $\beta$-catenin protein at lysine 49 and 345 (K49 and K345), which led to accumulation of $\beta$-catenin and eventually promoted osteogenesis [51].

Histone methylation is another histone modification that regulates gene expression during osteogenesis. Histone methyltransferases (HMTs) transfer up to three methyl groups to histone proteins, commonly at lysine residues, in contrast to histone demethylases (HDMs) that remove the methyl groups. These modifications activate or repress transcription depending on the location of the methylation [52]. The impact of histone methylation during MSC osteogenic differentiation has been the focus of a number of studies. Hassan et al. reported that HOXA10, a key gene for embryonic patterning of skeletal elements, was involved in differentiation of MSCs to the osteogenic lineage through activation of the Runx2, ALP, OCN, and BSP genes. They found that these effects were mediated by hyperacetylation of whole chromatin and H3K4 hypermethylation of these genes [53]. Higashihori et al. reported that H3K9 mono- and dimethyltransferase G9a was involved in osteogenesis regulation by twist gene repression [54]. HDMs have been shown to play an important role in osteodifferentiation of MSCs isolated from patients with oculo-facio-cardio-dental (OFCD) syndrome. Patients with OFCD have the BCL-6 corepressor (BCOR) mutation, which is characterized by canine teeth with long roots and craniofacial defects. MSCs obtained from these 
subjects had H3K4 and H3K36 hypermethylation at promoter of the AP2a gene. AP2a is an essential transcription factor for craniofacial development [55].

Zhang et al. demonstrated that JMJD3 (KDM6B), an H3K27me3 demethylase, was necessary for both intramembranous and endochondral ossification. JMJD3 might act as a co-activator of Runx2, and their cooperation promoted osteoblast differentiation and bone formation in mice [56].

H3K27me3 (repressive mark) has an important function in osteogenesis regulation. This epigenetic mark is stimulated by enhancer of zeste homology 2 (EZH2), an HMT, and is removed by lysine demethylase 6A (KDM6A). Ye et al. reported that the HDMs, KDM4B and KDM6B, regulated DLX and HOX gene expressions by removing $\mathrm{H} 3 \mathrm{~K} 9 \mathrm{me} 3$ and $\mathrm{H} 3 \mathrm{~K} 27 \mathrm{me} 3$, respectively, which indicated their pivotal role in osteogenic commitment of MSCs [57]. EZH2 and KDM6A also act as epigenetic switches to determine the cell fate in an osteoadipo lineage. EZH2 and KDM6A influence the levels of $\mathrm{H} 3 \mathrm{~K} 27 \mathrm{me} 3$ on the promoters of master regulatory genes. Enhanced expression of EZH2 in MSC stimulates adipogenesis in vitro and inhibits the osteogenic differentiation potential both in vitro and in vivo, whereas KDM6A acts in the opposite manner [8]. Therefore, both histone acetylation and methylation are important in osteogenic differentiation because they control osteogenic gene expressions. The histone modification status determines the fate of MSCs; therefore, we could change the cellular fate by changing gene expressions via artificial intervention.

\section{Chromatin remodeling}

Chromatin remodeling is the dynamic modification of chromatin by which nucleosomes move to a new location on the genomic DNA, which induces chromatin reconstruction to access DNA and control gene expression [58]. Reconstructed chromatin supplies required energy from ATP hydrolysis [59].

ATP-dependent chromatin remodelers are categorized into four distinct families: switch/sucrose-non-fermenting (SWI/SNF), imitation switch (ISWI), chromodomainhelicase-DNA-binding (CHD), and inositol requiring 80 (INO80) [60]. Other major chromatin remodeling proteins include the polycomb group (PcG) and trithorax group (TrxG) [61]. The PcG complex is involved in regulation of osteogenic differentiation of MSCs. PcG proteins form multi-protein complexes, termed polycomb-repressive complexes (PRCs). PRC2 contains EZH2, embryonic development protein (Eed), and suppressor of zeste12 (Suz12). Wei et al. investigated cyclin dependent kinase 1 (CDK1)-dependent phosphorylation of EZH2. They observed disruption of EZH2 binding with the other PRC2 components. Repression of EZH2 methyltransferase activity caused enhanced osteogenic differentiation of MSCs [62]. The role of CHD7 in osteogenesis was also supported by $\mathrm{Yi}$ et al. Binding of $\mathrm{CHD} 7$ to the enhancer region of sp7 was necessary for osteogenesis of human MSCs [59].

\section{MicroRNAs}

miRNAs are endogenous small non-coding RNAs $\sim 20$ nucleotides long that post-transcriptionally regulate gene expression. miRNAs perform their actions through interaction with sites of antisense complementarity in $3^{\prime}$ untranslated regions (UTRs) of specific target mRNAs. They cause degradation of the target mRNAs or translational suppression depending on the degree of miRNAmRNA complementarity [63, 64]. In humans, miRNAs target and regulate approximately more than $60 \%$ of genes responsible for protein production [65]. They contribute to the regulation of other epigenetic mechanisms such as histone acetylation and methylation [66, 67]. miRNAs act as positive or negative regulators of osteodifferentiation processes. The role of miRNAs in modulation of osteoblast differentiation of MSCs has been reported (Table 1).

Collectively, the abovementioned studies illustrated that epigenetic factors regulate genes, transcription factors, and signaling pathways. Precise knowledge of epigenetic patterns in MSCs before and after differentiation is necessary to improve efficient differentiation of MSCs. These findings enable us to discover regulation of osteogenesis via epigenetic modifications. In addition, they provide clues to discover novel treatments for bone defects by targeting specific regulators involved in osteogenesis and can help us to better control the fate of MSCs in cell-based therapy and advances in regenerative medicine and tissue engineering.

\section{Epigenetic modifiers, known as epidrugs}

The results of various experiments show that growth factors, peptides, small molecule, and epidrugs, as chemical compounds, play important roles in targeted osteogenesis. These compounds affect genes and transcription factors, and can induce MSC differentiation to osteoblasts. Some have been assessed in the in vitro studies and in vivo (animal models). However, only a few of these components have reached the clinical trial stage [81]. Table 2 lists some of the osteogenic components that induce osteogenic commitment of MSCs.

Epigenetics is defined as reversible heritable changes in gene expression without concomitant changes to the genomic sequence that engages in the biological process of mammalian development, and cellular differentiation and maintenance of tissue- and cell type-specific functions [95]. Extensive studies of cancers have revealed that human cancer cells harbor both genetic mutations 
Table 1 Various miRNAs regulating osteoblast differentiation of MSCs

\begin{tabular}{|c|c|c|c|}
\hline miRNA & Target & Feature & Reference(s) \\
\hline miR-2861 & HDAC5 & - Induces osteoblast differentiation & [68] \\
\hline miR-433-3p & DKK1/Wnt/ß-catenin pathway & $\begin{array}{l}\text { - Induces osteoblast differentiation through decreasing } \\
\text { DKK1 expression }\end{array}$ & [69] \\
\hline miR-199b-5p & GSK-3b & - Promotes osteoblast differentiation & {$[70]$} \\
\hline miR-15b & Smurf1 & $\begin{array}{l}\text { - Promotes osteoblast differentiation by indirectly protecting } \\
\text { Runx2 protein from Smurf1-mediated degradation }\end{array}$ & {$[71]$} \\
\hline miR-503 & Smurf1 & $\begin{array}{l}\text { - Induces osteogenic differentiation via suppressing Smurf1 } \\
\text { expression }\end{array}$ & [72] \\
\hline miR-22 & HDAC6 & $\begin{array}{l}\text { - Promotes osteogenesis and inhibits adipogenesis by } \\
\text { repressing HDAC6 }\end{array}$ & {$[66]$} \\
\hline miR-20a & PPARY, Bambi, and Crim1 & $\begin{array}{l}\text { - Promotes osteogenesis of hMSCs by upregulation of } \\
\text { BMP/Runx2 signaling }\end{array}$ & [73] \\
\hline miR-31, miR-93, and miR-145 & Osx & - Suppresses osteogenic differentiation & {$[74-76]$} \\
\hline miR-139-5p & Frizzled (FZD) & - Suppresses osteogenic differentiation & {$[77]$} \\
\hline miR-154-5p & Wnt/PCP signals & - Negative regulation of ADSC osteogenic differentiation & [78] \\
\hline miR-26a-5p & Wnt5a & - Suppresses osteogenic differentiation & {$[79]$} \\
\hline miR-204/211 & Runx2 & - Inhibits osteogenesis and promotes adipogenesis of BMSCs & {$[80]$} \\
\hline
\end{tabular}

and epigenetic aberrations [96, 97]. Accordingly, because of the pivotal reversible nature of epigenetic modifications, attention has been given to the application of epigenetic-based drugs (epidrugs). Epidrugs are drugs that target epigenetic marks, which are responsible for epigenetic alterations, such as DNMT and HDAC or mirRNAs. These drugs inhibit or activate diseaseassociated epigenetic proteins and lead to improvement, treatment, or prevention of diseases [95, 96]. Epidrugs, alone or with other anticancer drugs, have been used to

Table 2 Representative examples of osteoinductive components that have been investigated in osteogenesis and bone regeneration

\begin{tabular}{|c|c|c|c|}
\hline Components & Mechanism of action & Outcome & References \\
\hline \multicolumn{4}{|l|}{ Pre-clinical studies } \\
\hline Dexamethasone & Reduction of phosphorylation of ser 125 & Upregulated osteogenic markers & [82] \\
\hline Oxysterols & Induce the expression of the $\mathrm{Hh}$ target genes & Upregulated osteocalcin (OCN) and RUNX2 & [83] \\
\hline Purmorphamine & Activation of hedgehog signaling pathway & $\begin{array}{l}\text { Upregulated RUNX2 gene during osteoblast } \\
\text { differentiation }\end{array}$ & {$[84]$} \\
\hline Simvastatins & - & Enhanced RUNX2, osterix, OCN, and COlla1 & {$[85]$} \\
\hline W9 (YCWSQYLCY) peptide & $\begin{array}{l}\text { Activation of TGF and the PI3 kinase/Akt } \\
\text { signaling pathway }\end{array}$ & Promote osteogenesis & [86] \\
\hline IRW peptide & Activation of PI3K-Akt-RUNX2 pathway & Promote osteogenesis & {$[87]$} \\
\hline GRGDS peptide & - & Promote osteoblast adhesion and proliferation & {$[88]$} \\
\hline \multicolumn{4}{|l|}{ Clinical studies } \\
\hline SP1 & $\begin{array}{l}\text { Reduction of osteoclast deposition on bone } \\
\text { surfaces }\end{array}$ & Bone regeneration & {$[89]$} \\
\hline BMP-2/7 & - & Stimulate osteogenesis & {$[90]$} \\
\hline Fingolimod (FTY720) & $\begin{array}{l}\text { Immunomodulating drug derived from the } \\
\text { natural product myriocin also known as } \\
\text { fingolimod or Gilenya }\end{array}$ & Enhanced bone formation & [91] \\
\hline PDGF & - & $\begin{array}{l}\text { Comparable fusion rates and less pain in group } \\
\text { with PDGF-BB treatment as compared with } \\
\text { autograft treatment group }\end{array}$ & {$[92]$} \\
\hline FGF-2 & - & Enhance healing of periodontal defects & [93] \\
\hline P-15 & - & $\begin{array}{l}\text { Significant increase in bone mineral density of } \\
\text { bone around the implants }\end{array}$ & {$[94]$} \\
\hline
\end{tabular}


treat cancers where epigenetic regulation has a key role [98]. For example, 5-azacitidine (Vidaza) is an FDAapproved drug for myelodysplastic syndrome (MDS) and is one of the DNMT inhibitors (DNMTi). This drug has improved the quality of life for patients with MDS [99]. 5-Aza-2'-deoxycytidine (5-Aza-dC, decitabine, Dacogen), the deoxy form of 5-azacitidine, has been used to treat ovarian cancer. It has passed a phase I clinical trial for hematopoietic malignancies [100, 101]. Dysregulation of epigenetic modifications plays a role in other conditions, including inflammation, obesity, type 2 diabetes, dyslipidemia, cardiovascular diseases, neurological disorders, and metabolic disorders [102]. Epidrugs that have the capability to improve the epigenetic imbalances in these disorders are potentially ideal candidates for future treatments.

HDACs modulate gene expression. Histone deacetylase inhibitors (HDACi) alter gene expression and are being considered as favorable drugs for the treatment of malignancy. HDACi are divided into several classes: hydroxamic acids, cyclic peptides, short-chain fatty acids, and epoxides. These inhibitors arrest cell growth and induce differentiation or apoptosis of cancer cells both in vitro and in vivo [103]. Several HDACi such as valproic acid (VPA), suberoylanilide hydroxamic acid (SAHA, vorinostat), and entinostat have been used to treat MDS, cutaneous $\mathrm{T}$ cell lymphoma, and breast cancer, respectively [104-106]. In addition to HDACi, the EZH2 inhibitors EPZ-6438, GSK126, GSK343, and UNC1999 have also been used in cancer therapy [96] .

miRNAs are another important aspect of epigenetic regulation in cancers. The expression profiles of miRNAs deregulate during oncogenesis. Hence, Epi-miRs open up new horizons for novel cancer therapies [107]. The results of a number of studies indicate that miRNA expression is modulated by other epigenetic processes such as DNA methylation and histone modification in cancer. For example, miR-31/-34/-145/-21/-125b/$181 \mathrm{a} /-141$ are downregulated in various cancers. The epigenetic drug 5-aza-2'-deoxycytidine has been used to modulate their expressions [96].

Despite promising reports on the potential application of epidrugs as therapeutic strategies, there is significant concern that surrounds the unwanted adverse and offtarget effects. Hematologic complications, such as bleeding and anemia, can occur following treatment with DNMTi [108]. In mouse RMS cells, 5-Aza-dC promotes metastasis via reactivation of the pro-metastatic Ezrin gene [109]. Unfavorable adverse effects are a concern with HDACi. Most HDACi are non-selective and target multiple classes or isozymes of HDACs (pan-HDACi), and result in toxic adverse effects. The most common complaints associated with SAHA are anemia, increased blood urea, anorexia, hyperglycemia, thrombocytopenia, fatigue, and nausea. However, the toxic effects of SAHA were dose-dependent and SAHA was more efficient at a lower dose [110]. Usual adverse effects of another HDACi, VPA, included hepatic toxicity, gastrointestinal disorders, blood dyscrasias, and hyperammonemia. These adverse effects were mild, dose-dependent, and reversible. However, valproate-induced hyperammonemic encephalopathy (VHE) is a rare, concerning adverse effect [111]. Also, commonly reported adverse effects of entinostat include fatigue and gastrointestinal, hematologic, and metabolic disorders, which appear to be concentration-dependent [112]. The therapeutic approaches in the base of miRNAs as epidrugs, as well as the mentioned epidrugs, suffer from off-target problems. A single miRNA can target multiple genes and cause unwanted effects [113].

In order to reduce the unwanted adverse effects, it is necessary to precisely recognize epidrug targets in order to design selective and class or isoform-specific enzyme inhibitors for specific cells. Also, the use of a suitable drug delivery system with controlled local, sustained release and evaluation of the lowest effective dose might overcome this issue.

\section{Epidrugs as regulators of osteogenesis}

MSCs are of tremendous interest to stem cell-based transplantation therapy; newly emerging research has implicated the important role of epigenetic mechanisms in regulating mesodermal lineage determination and differentiation. Evidence indicates that the induction of MSC differentiation toward osteoblasts is supported by epigenetic regulations [114].

There is growing evidence that pertains to the effect of epidrugs on bone formation as well as cancer clinical therapy. A number of studies have highlighted the role of DNMTi during osteogenesis. Chen et al. reported the role of 5-Aza-dC as a lineage determinator between adipogenesis and osteoblastogenesis. They found that it promotes osteoblastogenesis by demethylation and upregulation of the Wnt10a gene and osteoblastogenic markers ALP, OSX, Twist1, and Dlx5 in 3T3-L1 preadipocytes and the ST2 MSC line [115]. Lee et al. examined the effect of 5 -Aza-dC on $\mathrm{C} 2 \mathrm{C} 12$ cells. They observed that 5-Aza-dC demethylated promoters of the Dlx5 and Osx genes in a dose- and time-dependent manner. The expression levels of the ALP and OCN genes increased after 5-Aza-dC treatment [116]. Similarly, pretreatment of mouse bone marrow MSCs with 5-azacytidine increased expressions of DLX5, Runx2, COL1A1, Osx, and $\mathrm{OCN}$, and accelerated osteogenesis. Hypomethylation of the DLX5 promoter occurred after pretreatment with 5azacytidine as evidenced by the bisulfite sequencing technique [117]. 
In addition to DNMTi, some studies have focused on HDACi and their role during differentiation of MSCs to an osteoblast lineage. VPA is a short-chain branched fatty acid prescribed for treatment of epilepsy and neurological disorders. Cho et al. reported that treatment of human adipose tissue-derived stromal cells (hADSCs) with VPA as an HDAC inhibitor increased the expressions of OSX, OPN, Runx2, and BMP2 during osteogenesis, which indicates a positive role for VPA in osteogenesis [118]. Paino et al. assessed the impact of VPA on human dental pulp stem cells. They reported that VPA significantly enhanced matrix mineralization by enhancing OPN and bone sialoprotein (BSP) expressions, but had a negative effect on late-stage marker of differentiation $(\mathrm{OCN})$, which indicated that VPA did not impact the terminal step of osteogenesis. This effect was strongly related to inhibition of HDAC2 and has implied that HDAC2 is a fundamental enzyme for osteogenesis [103]. La Noce et al. demonstrated that treatment of human dental pulp stem cells with VPA caused wellorganized bone tissue formation after subcutaneous implantation of the cells into immunodeficient mice, despite a decrease in OCN expression [119].

SAHA is another HDACi that is clinically used to treat cancer. In a study, the treatment of C57BL/6J mice with SAHA caused decreased mineralization and OPN, COL1A1, and OCN gene expression, and eventually led to bone loss in rodents [120]. In contrast, other researches showed that optimum dose of SAHA had no negative effects on bone formation and could promote osteogenesis via upregulation of Runx2 and BMP-2dependent ALP activity in both human bone marrow MSCs and an osteoporotic mice model [121, 122]. These contradicting results for SAHA in osteogenesis indicate that it has a dose-dependent function during osteodifferentiation.

Trichostatin A (TSA), a widely applied $\mathrm{HDACi}$, has been assessed in bone studies. Boer et al. reported that ALP expression and bone formation were dramatically enhanced by TSA-treated human MSCs in an ex vivo cultured mouse calvaria but implantation of these cells into immune-deficient mice did not show any significant results [123]. TSA also promoted rat adipose-derived stem cell (ADSC) osteogenic differentiation by hyperacetylation of the Runx2 promoter in a BMP signalingdependent manner [124]. Hu et al. reported that TSA potentiated BMP9-induced ALP activity, OCN, OPN, and matrix mineralization in mouse MSCs. Also, findings from a fetal limb explant culture showed the role for TSA in endochondral bone formation [125].

Sodium butyrate $(\mathrm{NaBu})$ is a short-chain fatty acid that plays a critical function in the homeostasis of the gastrointestinal tract; $\mathrm{NaBu}$ inhibits HDACs. It has been shown that $\mathrm{NaBu}$ modulates osteogenic differentiation in hMSCs by an ERK-dependent Runx2 activation [126]. $\mathrm{NaBu}$, by increasing $\mathrm{H} 3 \mathrm{~K} 9 \mathrm{ac}$ and decreasing H3K9me onto the Runx2 promoter, has been shown to enhance rat ADSC osteogenesis [127]. Ali et al. assessed the effect of abexinostat, an $\mathrm{HDACi}$, on osteoblast differentiation of human MSCs. They observed that abexinostat enhanced the expression levels of the ALP and Osx genes through the WNT signaling pathway [128].

Besides the effect of HDACi during osteoblast differentiation, several studies were conducted to assess inhibition of the EZH2 epigenetic factor, a novel therapeutic target for improvement of bone formation. Inhibition of EZH2-mediated 3-deazaneplanocin A (DZNep) promoted osteoblast differentiation of hMSCs [8]. Jing et al. sought to determine a correlation to inhibition of EZH2 via DZNep during osteoporosis. They reported that knockdown of EZH2 via DZNep decreased the level of H3K27me3 on the promoters of Wnt genes and recovered mouse osteoporotic BMSCs in vitro and in vivo [129]. GSK126, another EZH2 inhibitor, showed similar results and enhanced osteogenic commitment of human adipose-derived MSCs (hAMSCs). The results indicated that GSK126 decreased H3K27me3 levels by inhibition of EZH2, which led to promotion of ALP and Runx2 expressions [130]. More recently, Khanban et al. have reported the impact of the G9A inhibitor A366 on osteogenic potential of BMSCs. They found that Runx2, ALP, COL1A1, Osx, and OCN gene expression levels and osteogenesis decreased in BMSCs derived from A366-treated rats [131]. Table 3 lists some epidrugs and their targets involved in osteogenesis. Epidrugs can be considered to be suitable choices for targeting epigenetic aberrations in the treatment of bone defects and efficient differentiation of MSCs for application in regenerative medicine. Figure 2 shows the impact of epidrugs on the promotion of osteogenesis.

The survival of MSCs is a significant point to be made about the use of epidrugs in promotion of MSC differentiation. The results of studies have shown that the viability of MSCs was affected by various doses of epidrugs; increased doses had a negative impact on MSC survival $[117,119,132]$. An evaluation of the effect of VPA and NaBu on MSCs showed a dosedependent reduction in MSC proliferation. In addition, the proliferation of MSCs from diverse origins (umbilical cord blood, adipose tissue, and bone marrow) has different sensitivities to epidrugs [133]. In a recent study, Salami et al. have reported that, in addition to the concentration of VPA, the medium context could have a key role in the effects of VPA on Wharton's Jelly MSCs [134]. These findings highlight the importance of determining a suitable dose of epidrugs with minimal cytotoxicity in different cells and contexts before their use in vitro and in vivo. 
Table 3 Various epidrugs targeting osteogenesis

\begin{tabular}{|c|c|c|c|c|}
\hline Epidrug & Alternate name & Target(s) & Impact on osteogenesis & References \\
\hline 5-Azacytidine & Vidaza & DNMT & $\begin{array}{l}\text { Upregulation of osteogenic gene markers (ALP, Dl×5, Runx2, } \\
\text { Col1a1, osterix, and osteocalcin) }\end{array}$ & {$[117]$} \\
\hline 5-Aza-2'-deoxycytidine & Decitabine & DNMT & $\begin{array}{l}\text { Upregulation of Wnt10a, a key factor determining the fate of } \\
\text { the mesenchymal lineage toward osteoblasts } \\
\text { Increased Dlx5 and Osx genes }\end{array}$ & {$[115,116]$} \\
\hline Valproic acid & - & HDAC & $\begin{array}{l}\text { Enhanced BMP2 expression } \\
\text { Enhanced matrix mineralization } \\
\text { Negative effect on OCN }\end{array}$ & {$[103,118]$} \\
\hline Vorinostat & SAHA & HDAC & $\begin{array}{l}\text { Inhibition of immature osteoblasts } \\
\text { Induction of osteogenic markers (RUNX2, BMP-2, and ALP) }\end{array}$ & [120-122] \\
\hline Trichostatin A & TSA & HDAC & $\begin{array}{l}\text { Promotion of osteogenic differentiation via increased in osteocalcin, } \\
\text { osteopontin, and ALP }\end{array}$ & [123-125] \\
\hline Sodium butyrate & - & HDAC & Promotion of osteogenic differentiation via RUNX2 & {$[126,127]$} \\
\hline Abexinostat & - & HDAC & Increased OSX and ALP & [128] \\
\hline GSK126 & - & HMT & $\begin{array}{l}\text { Acceleration of osteogenic differentiation by regulation of Bglap, } \\
\text { Sparc, Spp1, and Ibsp genes }\end{array}$ & [130] \\
\hline 3-Deazaneplanocin A & DZNep & НMT & Upregulation of Wnt1, Wnt6, and Wnt10a osteogenic genes & [129] \\
\hline
\end{tabular}

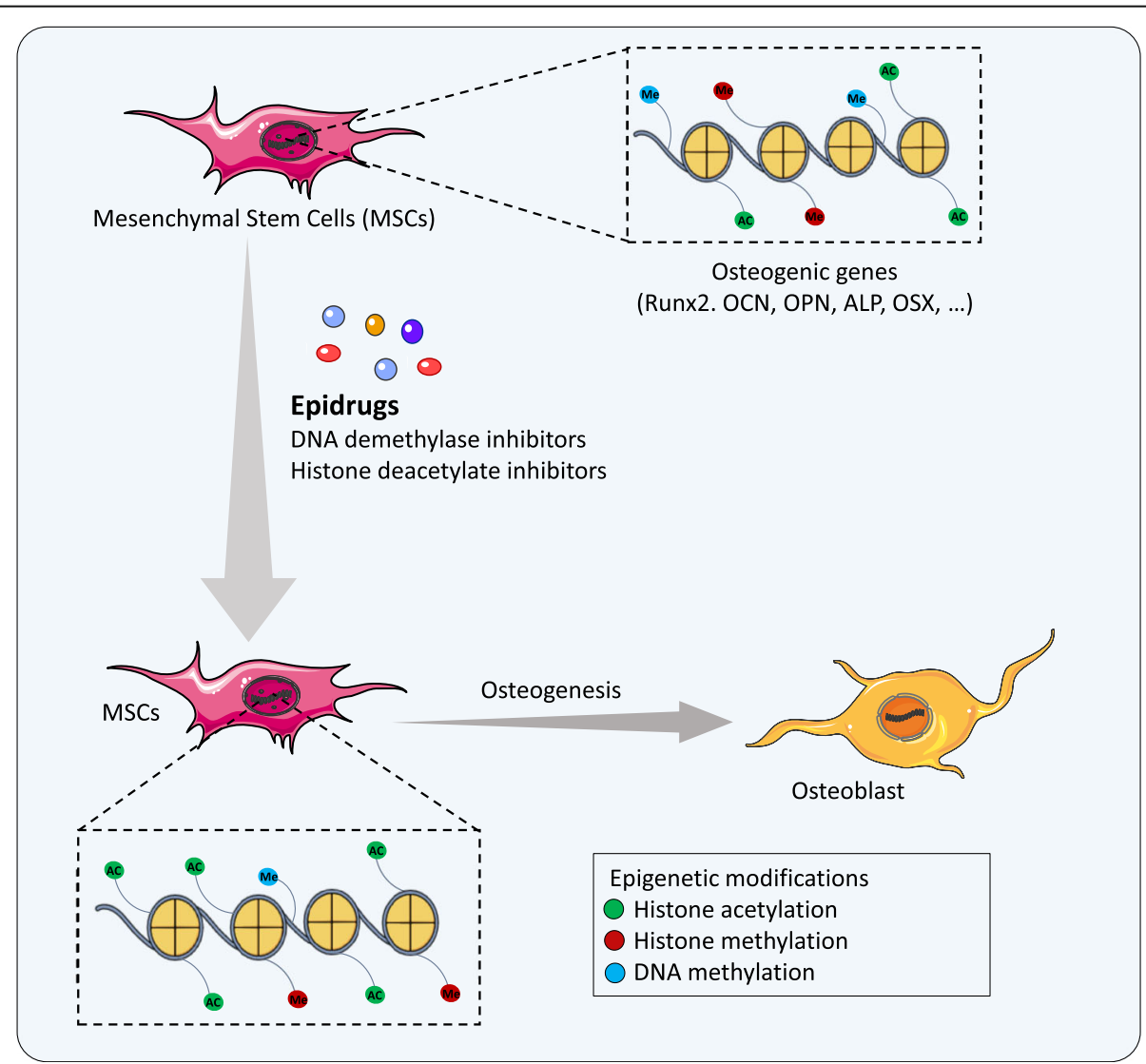

Fig. 2 Schematic presentation of epidrugs' effect on the promotion of osteogenesis. After treatment of MSCs with epidrugs, there is a decrease in the epigenetic marks responsible for the silencing genes (DNA methylation, histone methylation) and an increase in gene-activating epigenetic marks (histone acetylation) in osteogenic genes, which result in promotion of osteogenesis 


\section{Future trends and concluding remarks}

MSC characteristics include their ability to be isolated from various sources, multipotent properties, immunosuppressive capacity, no risk of tumorigenesis, and easy expansion in vitro. These characteristics make them ideal candidates for regenerative medicine and tissue engineering. However, the use of these cells for stem cellbased therapy still requires a rigorous understanding of the mechanisms that occur during in vitro and in vivo MSC differentiation. Osteogenesis is controlled by numerous genes, transcription factors, signaling pathways, and epigenetic mechanisms. Nevertheless, detailed knowledge of epigenetic regulation of osteoblast differentiation is obscure. Hence, a novel insight into prevention and treatment of disease-associated epigenetic defects such as cancer would include the identification and targeting of epigenetic modification enzymes by epidrugs. Recently, the use of epidrugs to treat various cancers has been studied. Some have been approved by the FDA, and several are in phase I/II studies. The role of some epigenetic enzyme inhibitors has been addressed in osteoblast differentiation of MSCs, and the results have shown that some of these epidrugs improve osteogenesis and bone formation via alterations in epigenetic arrangements. According to the emerging knowledge on the role of these epigenetic modifiers in osteogenesis, epidrugs can be potentially used to improve in vitro and in vivo osteogenic differentiation with the goal to enhance the capability of MSCs to be used in tissue engineering and regenerative medicine. Epidrugs have the ability to be used as treatment for metabolic bone disorders such as osteoarthritis and osteoporosis; however, cytotoxicity is the main problem for their clinical use. In order to overcome the adverse effects of an epidrug, the first step would be to identify which epigenetic marker should be targeted in a certain disease and use its class or isoform-specific enzyme inhibitors. Furthermore, additional research is needed to determine the optimal dose and discover the appropriate epidrug transfer systems prior to their clinical applications in bone tissue engineering. Currently, a gap exists between our knowledge and clinical applications, and a more thorough investigation in this context would be essential prior to the use of epidrugs as therapy. It is, therefore, necessary that further research should be conducted to fully understand the epigenetic changes that occur with bone disorders and to recognize epigenetic patterns in genes responsible for their repair and rejuvenation.

\section{Acknowledgements \\ We are grateful to Zeynab Ghorbaninejad for preparing the schematic figures.}

Authors' contributions

MG, MKS, SH, and MBE designed the concept. MG and MKS searched the literature. MG and MK wrote the manuscript and created the figure and table. $\mathrm{SH}$ and MBE revised the manuscript. The authors read and approved the final manuscript.

Funding

Funding information is not applicable to this article.

Availability of data and materials

Data sharing is not applicable to this article as no datasets were generated or analyzed during the current study.

Ethics approval and consent to participate

Not applicable.

Consent for publication

Not applicable.

\section{Competing interests}

The authors declare that they have no competing interests.

\section{Author details}

${ }^{1}$ Basic and Molecular Epidemiology of Gastrointestinal Disorders Research Center, Research Institute for Gastroenterology and Liver Diseases, Shahid Beheshti University of Medical Sciences, Tehran, Iran. ${ }^{2}$ Department of Stem Cells and Developmental Biology, Cell Science Research Center, Royan Institute for Stem Cell Biology and Technology, ACECR, Tehran, Iran. ${ }^{3}$ Department of Genetics, Reproductive Biomedicine Research Center, Royan Institute for Reproductive Biomedicine, ACECR, Tehran, Iran. ${ }^{4}$ Department of Cell Engineering, Cell Science Research Center, Royan Institute for Stem Cell Biology and Technology, ACECR, Tehran, Iran.

Received: 29 July 2020 Accepted: 5 October 2020

Published online: 28 October 2020

\section{References}

1. Hosseini S, Taghiyar L, Safari F, Eslaminejad MB. Regenerative medicine applications of mesenchymal stem cells. Cell Biol Translational Med. 2018;2: 115-41 Springer.

2. Garg P, Mazur MM, Buck AC, Wandtke ME, Liu J, Ebraheim NA. Prospective review of mesenchymal stem cells differentiation into osteoblasts. Orthop Surg. 2017:9(1):13-9.

3. Hosseini S, Naderi-Manesh H, Vali H, Eslaminejad MB, Sayahpour FA, Sheibani $\mathrm{S}$, et al. Contribution of osteocalcin-mimetic peptide enhances osteogenic activity and extracellular matrix mineralization of human osteoblast-like cells. Colloids Surf B: Biointerfaces. 2019;173:662-71.

4. Shen J, Hovhannisyan H, Lian JB, Montecino MA, Stein GS, Stein JL, et al. Transcriptional induction of the osteocalcin gene during osteoblast differentiation involves acetylation of histones h3 and h4. Mol Endocrinol. 2003;17(4):743-56

5. Reik W. Stability and flexibility of epigenetic gene regulation in mammalian development. Nature. 2007:447(7143):425-32.

6. Han JW, Yoon Y-S. Epigenetic landscape of pluripotent stem cells. Antioxid Redox Signal. 2012;17(2):205-23.

7. Fragale A, Romagnoli G, Licursi V, Buoncervello M, Del Vecchio G, Giuliani C, et al. Antitumor effects of Epidrug/IFNa combination driven by modulated gene signatures in both colorectal cancer and dendritic cells. Cancer Immunol Res. 2017:5(7):604-16.

8. Hemming S, Cakouros D, Isenmann S, Cooper L, Menicanin D, Zannettino A, et al. EZH2 and KDM6A act as an epigenetic switch to regulate mesenchymal stem cell lineage specification. Stem Cells. 2014;32(3):802-15.

9. Jensen ED, Gopalakrishnan R, Westendorf JJ. Regulation of gene expression in osteoblasts. Biofactors. 2010;36(1):25-32.

10. Javed A, Chen H, Ghori FY. Genetic and transcriptional control of bone formation. Oral Maxillofac Surg Clin. 2010;22(3):283-93.

11. Bruderer M, Richards R, Alini M, Stoddart M. Role and regulation of RUNX2 in osteogenesis. Eur Cell Mater. 2014;28(28):269-86.

12. Ducy P, Zhang R, Geoffroy V, Ridall AL, Karsenty G. Osf2/Cbfa1: a transcriptional activator of osteoblast differentiation. Cell. 1997;89(5):747-54.

13. Kanno T, Takahashi T, Tsujisawa T, Ariyoshi W, Nishihara T. Mechanical stressmediated Runx2 activation is dependent on Ras/ERK1/2 MAPK signaling in osteoblasts. J Cell Biochem. 2007;101(5):1266-77. 
14. Ortuño MJ, Susperregui AR, Artigas N, Rosa JL, Ventura F. Osterix induces Colla1 gene expression through binding to Sp1 sites in the bone enhancer and proximal promoter regions. Bone. 2013;52(2):548-56.

15. Nakashima K, Zhou X, Kunkel G, Zhang Z, Deng JM, Behringer RR, et al. The novel zinc finger-containing transcription factor osterix is required for osteoblast differentiation and bone formation. Cell. 2002;108(1):17-29.

16. Nishimura R, Hata K, Ikeda F, Ichida F, Shimoyama A, Matsubara T, et al. Signal transduction and transcriptional regulation during mesenchymal cell differentiation. J Bone Miner Metab. 2008;26(3):203.

17. Plaisant M, Fontaine C, Cousin W, Rochet N, Dani C, Peraldi P. Activation of hedgehog signaling inhibits osteoblast differentiation of human mesenchymal stem cells. Stem Cells. 2009;27(3):703-13.

18. Ji Y, Ke Y, Gao S. Intermittent activation of notch signaling promotes bone formation. Am J Transl Res. 2017;9(6):2933.

19. Kohn AD, Moon RT. Wht and calcium signaling: $\beta$-catenin-independent pathways. Cell Calcium. 2005;38(3-4):439-46.

20. McSheehy $\mathrm{P}$, Chambers T. Osteoblastic cells mediate osteoclastic responsiveness to parathyroid hormone. Endocrinology. 1986;118(2):824-28.

21. Datta NS, Pettway GJ, Chen C, Koh AJ, McCauley LK. Cyclin D1 as a target for the proliferative effects of PTH and PTHrP in early osteoblastic cells. J Bone Miner Res. 2007;22(7):951-64.

22. Senarath-Yapa K, McArdle A, Renda A, Longaker MT, Quarto N. Adiposederived stem cells: a review of signaling networks governing cell fate and regenerative potential in the context of craniofacial and long bone skeletal repair. Int J Mol Sci. 2014;15(6):9314-30.

23. Liu Z, Xu J, Colvin JS, Ornitz DM. Coordination of chondrogenesis and osteogenesis by fibroblast growth factor 18. Genes Dev. 2002;16(7):859-69.

24. Oshimori N, Fuchs E. The harmonies played by TGF- $\beta$ in stem cell biology. Cell Stem Cell. 2012;11(6):751-64.

25. Fujii M, Takeda K, Imamura T, Aoki H, Sampath TK, Enomoto S, et al. Roles of bone morphogenetic protein type I receptors and Smad proteins in osteoblast and chondroblast differentiation. Mol Biol Cell. 1999;10(11):3801-13.

26. Carreira A, Lojudice F, Halcsik E, Navarro R, Sogayar M, Granjeiro J. Bone morphogenetic proteins: facts, challenges, and future perspectives. J Dent Res. 2014;93(4):335-45.

27. Long F, Chung U-I, Ohba S, McMahon J, Kronenberg HM, McMahon AP. Ihh signaling is directly required for the osteoblast lineage in the endochondral skeleton. Development. 2004;131(6):1309-18.

28. De Jong D, Steegenga W, Hendriks J, Van Zoelen E, Olijve W, Dechering K. Regulation of Notch signaling genes during BMP2-induced differentiation of osteoblast precursor cells. Biochem Biophys Res Commun. 2004;320(1):100-7.

29. Qiu T, Wu X, Zhang F, Clemens TL, Wan M, Cao X. TGF- $\beta$ type II receptor phosphorylates PTH receptor to integrate bone remodelling signalling. Nat Cell Biol. 2010;12(3):224-34.

30. Jiang $T$, Ge S, Shim YH, Zhang C, Cao D. Bone morphogenetic protein is required for fibroblast growth factor 2-dependent later-stage osteoblastic differentiation in cranial suture cells. Int J Clin Exp Pathol. 2015;8(3):2946.

31. Kamiya N, Kobayashi T, Mochida Y, Yu PB, Yamauchi M, Kronenberg HM, et al. Wnt inhibitors Dkk1 and Sost are downstream targets of BMP signaling through the type IA receptor (BMPRIA) in osteoblasts. J Bone Miner Res. 2010;25(2):200-10

32. Mortada I, Mortada R. Epigenetic changes in mesenchymal stem cells differentiation. Eur J Med Genet. 2018:61(2):114-8.

33. Daniunaite K, Serenaite I, Misgirdaite R, Gordevicius J, Unguryte A, FleuryCappellesso $\mathrm{S}$, et al. Epigenetic regulation of human adipose-derived stem cells differentiation. Mol Cell Biochem. 2015;410(1-2):111-20.

34. Jones PA. Functions of DNA methylation: islands, start sites, gene bodies and beyond. Nat Rev Genet. 2012;13(7):484-92.

35. Chen T, Ueda Y, Dodge JE, Wang Z, Li E. Establishment and maintenance of genomic methylation patterns in mouse embryonic stem cells by Dnmt3a and Dnmt3b. Mol Cell Biol. 2003;23(16):5594-605.

36. Arnsdorf EJ, Tummala P, Castillo AB, Zhang F, Jacobs CR. The epigenetic mechanism of mechanically induced osteogenic differentiation. J Biomech. 2010;43(15):2881-6.

37. Delgado-Calle J, Sañudo C, Sánchez-Verde L, García-Renedo RJ, Arozamena J, Riancho JA. Epigenetic regulation of alkaline phosphatase in human cells of the osteoblastic lineage. Bone. 2011;49(4):830-8.

38. Zhang R-P, Shao J-Z, Xiang L-X. GADD45A protein plays an essential role in active DNA demethylation during terminal osteogenic differentiation of adipose-derived mesenchymal stem cells. J Biol Chem. 2011;286(47):41083-94.
39. Sepulveda H, Villagra A, Montecino M. Tet-mediated DNA demethylation is required for SWI/SNF-dependent chromatin remodeling and histonemodifying activities that trigger expression of the Sp7 osteoblast master gene during mesenchymal lineage commitment. Mol Cell Biol. 2017;37(20): e00177-17.

40. Wakitani S, Yokoi D, Hidaka Y, Nishino K. The differentially DNA-methylated region responsible for expression of runt-related transcription factor 2. J Vet Med Sci. 2017;79(2):230-7.

41. Chen JR, Zhang J, Lazarenko OP, Kang P, Blackburn ML, Ronis MJ, et al. Inhibition of fetal bone development through epigenetic down-regulation of HoxA10 in obese rats fed high-fat diet. FASEB J. 2012;26(3):1131-41.

42. Tarfiei G, Noruzinia M, Soleimani M, Kaviani S, Maymand MM, Hagh MF, et al. ROR2 promoter methylation change in osteoblastic differentiation of mesenchymal stem cells. Cell J (Yakhteh). 2011;13(1):11.

43. Yang R, Yu T, Kou X, Gao X, Chen C, Liu D, et al. Tet1 and Tet2 maintain mesenchymal stem cell homeostasis via demethylation of the P2rX7 promoter. Nat Commun. 2018:9(1):1-14.

44. Kouzarides T. Chromatin modifications and their function. Cell. 2007;128(4): 693-705.

45. Huang H, Sabari BR, Garcia BA, Allis CD, Zhao Y. SnapShot: histone modifications. Cell. 2014;159(2):458 e1.

46. Kuo MH, Allis CD. Roles of histone acetyltransferases and deacetylases in gene regulation. Bioessays. 1998;20(8):615-26.

47. Tan J, Lu J, Huang W, Dong Z, Kong C, Li L, et al. Genome-wide analysis of histone $\mathrm{H} 3$ lysine9 modifications in human mesenchymal stem cell osteogenic differentiation. PLoS One. 2009;4(8):e6792.

48. Zhang P, Liu Y, Jin C, Zhang M, Lv L, Zhang X, et al. Histone H3K9 acetyltransferase PCAF is essential for osteogenic differentiation through bone morphogenetic protein signaling and may be involved in osteoporosis. Stem Cells. 2016:34(9):2332-41.

49. Sepulveda H, Aguilar R, Prieto CP, Bustos F, Aedo S, Lattus J, et al. Epigenetic signatures at the RUNX2-P1 and Sp7 gene promoters control osteogenic lineage commitment of umbilical cord-derived mesenchymal stem cells. J Cell Physiol. 2017:232(9):2519-27.

50. Gordon JA, Hassan MQ, Koss M, Montecino M, Selleri L, Van Wijnen AJ, et al. Epigenetic regulation of early osteogenesis and mineralized tissue formation by a HOXA10-PBX1-associated complex. Cells Tissues Organs. 2011;194(2-4):146-50.

51. Simic P, Zainabadi K, Bell E, Sykes DB, Saez B, Lotinun S, et al. SIRT1 regulates differentiation of mesenchymal stem cells by deacetylating $\beta$ catenin. EMBO Mol Med. 2013;5(3):430-40

52. Avgustinova A, Benitah SA. Epigenetic control of adult stem cell function. Nat Rev Mol Cell Biol. 2016;17(10):643.

53. Hassan MQ, Tare R, Lee SH, Mandeville M, Weiner B, Montecino M, et al. HOXA10 controls osteoblastogenesis by directly activating bone regulatory and phenotypic genes. Mol Cell Biol. 2007;27(9):3337-52.

54. Higashihori N, Lehnertz B, Sampaio A, Underhill T, Rossi F, Richman J. Methyltransferase G9A regulates osteogenesis via twist gene repression. J Dent Res. 2017:96(10):1136-44.

55. Fan Z, Yamaza T, Lee JS, Yu J, Wang S, Fan G, et al. BCOR regulates mesenchymal stem cell function by epigenetic mechanisms. Nat Cell Biol. 2009;11(8):1002-9.

56. Zhang F, Xu L, Xu L, Xu Q, Karsenty G, Chen CD. Histone demethylase JMJD3 is required for osteoblast differentiation in mice. Sci Rep. 2015;5: 13418.

57. Ye L, Fan Z, Yu B, Chang J, Al Hezaimi K, Zhou X, et al. Histone demethylases KDM4B and KDM6B promotes osteogenic differentiation of human MSCs. Cell Stem Cell. 2012;11(1):50-61.

58. Ehrenhofer-Murray AE. Chromatin dynamics at DNA replication, transcription and repair. Eur J Biochem. 2004;271(12):2335-49.

59. Chen $Y$, Wang M, Chen D, Wang J, Kang N. Chromatin remodeling enzyme CHD7 is necessary for osteogenesis of human mesenchymal stem cells. Biochem Biophys Res Commun. 2016;478(4):1588-93.

60. Zhang P, Torres K, Liu X, Liu C-g, E Pollock R. An overview of chromatinregulating proteins in cells. Curr Protein Peptide Sci. 2016;17(5):401-10.

61. Im G-I, Shin K-J. Epigenetic approaches to regeneration of bone and cartilage from stem cells. Expert Opin Biol Ther. 2015;15(2):181-93.

62. Wei Y, Chen Y-H, Li L-Y, Lang J, Yeh S-P, Shi B, et al. CDK1-dependent phosphorylation of EZH2 suppresses methylation of $\mathrm{H} 3 \mathrm{~K} 27$ and promotes osteogenic differentiation of human mesenchymal stem cells. Nat Cell Biol. 2011;13(1):87-94. 
63. He L, Hannon GJ. MicroRNAs: small RNAs with a big role in gene regulation. Nat Rev Genet. 2004;5(7):522.

64. Ambros V. The functions of animal microRNAs. Nature. 2004;431(7006):350.

65. Friedman RC, Farh KK-H, Burge CB, Bartel DP. Most mammalian mRNAs are conserved targets of microRNAs. Genome Res. 2009;19(1):92-105.

66. Huang S, Wang S, Bian C, Yang Z, Zhou H, Zeng Y, et al. Upregulation of miR-22 promotes osteogenic differentiation and inhibits adipogenic differentiation of human adipose tissue-derived mesenchymal stem cells by repressing HDAC6 protein expression. Stem Cells Dev. 2012;21 (13):2531-40.

67. Huszar JM, Payne CJ. MIR146A inhibits JMJD3 expression and osteogenic differentiation in human mesenchymal stem cells. FEBS Lett. 2014;588(9):1850-6.

68. Li H, Xie H, Liu W, Hu R, Huang B, Tan Y-F, et al. A novel microRNA targeting HDAC5 regulates osteoblast differentiation in mice and contributes to primary osteoporosis in humans. J Clin Invest. 2009;119(12): 3666-77.

69. Tang X, Lin J, Wang G, Lu J. MicroRNA-433-3p promotes osteoblast differentiation through targeting DKK1 expression. PLoS One. 2017;12(6): e0179860.

70. Zhao R, Li Y, Lin Z, Wan J, Xu C, Zeng Y, et al. miR-199b-5p modulates

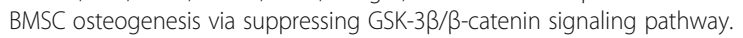
Biochem Biophys Res Commun. 2016;477(4):749-54.

71. Vimalraj S, Partridge NC, Selvamurugan N. A positive role of microRNA-15b on regulation of osteoblast differentiation. J Cell Physiol. 2014;229(9):1236-44.

72. Sun Y, Xu J, Xu L, Zhang J, Chan K, Pan X, et al. MiR-503 promotes bone formation in distraction osteogenesis through suppressing Smurf1 expression. Sci Rep. 2017;7(1):409.

73. Zhang J-F, Fu W-M, He M-L, Xie W-D, Lv Q, Wan G, et al. MiRNA-20a promotes osteogenic differentiation of human mesenchymal stem cells by co-regulating BMP signaling. RNA Biol. 2011;8(5):829-38.

74. Baglio SR, Devescovi V, Granchi D, Baldini N. MicroRNA expression profiling of human bone marrow mesenchymal stem cells during osteogenic differentiation reveals Osterix regulation by miR-31. Gene. 2013;527(1):321-31.

75. Yang $L$, Cheng P, Chen C, He HB, Xie GQ, Zhou HD, et al. miR-93/Sp7 function loop mediates osteoblast mineralization. J Bone Miner Res. 2012; 27(7):1598-606.

76. Jia J, Tian Q, Ling S, Liu Y, Yang S, Shao Z. miR-145 suppresses osteogenic differentiation by targeting Sp7. FEBS Lett. 2013;587(18):3027-31.

77. Long H, Sun B, Cheng L, Zhao S, Zhu Y, Zhao R, et al. miR-139-5p represses BMSC osteogenesis via targeting Wnt/ $\beta$-catenin signaling pathway. DNA Cell Biol. 2017:36(8):715-24.

78. Li J, Hu C, Han L, Liu L, Jing W, Tang W, et al. MiR-154-5p regulates osteogenic differentiation of adipose-derived mesenchymal stem cells under tensile stress through the Wnt/PCP pathway by targeting Wnt11. Bone. 2015;78:130-41.

79. Li S, Hu C, Li J, Liu L, Jing W, Tang W, et al. Effect of miR-26a-5p on the Wnt/Ca 2+ pathway and osteogenic differentiation of mouse adiposederived mesenchymal stem cells. Calcif Tissue Int. 2016;99(2):174-86.

80. Huang J, Zhao L, Xing L, Chen D. MicroRNA-204 regulates Runx2 protein expression and mesenchymal progenitor cell differentiation. Stem Cells. 2010;28(2):357-64.

81. Wang Y, Zhu G, Li N, Song J, Wang L, Shi X. Small molecules and their controlled release that induce the osteogenic/chondrogenic commitment of stem cells. Biotechnol Adv. 2015;33(8):1626-40.

82. Phillips JE, Gersbach CA, Wojtowicz AM, García AJ. Glucocorticoid-induced osteogenesis is negatively regulated by Runx2/Cbfa1 serine phosphorylation. J Cell Sci. 2006;119(3):581-91.

83. Jang WG, Kim EJ, Bae I-H, Lee K-N, Kim YD, Kim D-K, et al. Metformin induces osteoblast differentiation via orphan nuclear receptor SHPmediated transactivation of Runx2. Bone. 2011;48(4):885-93.

84. Oliveira F, Bellesini L, Defino H, da Silva HC, Beloti M, Rosa A. Hedgehog signaling and osteoblast gene expression are regulated by purmorphamine in human mesenchymal stem cells. J Cell Biochem. 2012;113(1):204-8.

85. Pagkalos J, Cha JM, Kang Y, Heliotis M, Tsiridis E, Mantalaris A. Simvastatin induces osteogenic differentiation of murine embryonic stem cells. J Bone Miner Res. 2010;25(11):2470-8.

86. Otsuki Y, li M, Moriwaki K, Okada M, Ueda K, Asahi M. W9 peptide enhanced osteogenic differentiation of human adipose-derived stem cells. Biochem Biophys Res Commun. 2018;495(1):904-10

87. Shang N, Bhullar KS, Hubbard BP, Wu J. Tripeptide IRW initiates differentiation in osteoblasts via the RUNX2 pathway. Biochim Biophys Acta Gen Subj. 2019;1863(6):1138-46.
88. Kim G-H, Park S-W, Lee K, Yun K-D, Kim H-S, Oh G-J, et al. Evaluation of osteoblast-like cell viability and differentiation on the Gly-Arg-Gly-Asp-Ser peptide immobilized titanium dioxide nanotube via chemical grafting. J Nanosci Nanotechnol. 2016;16(2):1396-9.

89. Segar CE, Ogle ME, Botchwey EA. Regulation of angiogenesis and bone regeneration with natural and synthetic small molecules. Curr Pharm Des. 2013;19(19):3403-19

90. Cipitria A, Reichert JC, Epari DR, Saifzadeh S, Berner A, Schell H, et al. Polycaprolactone scaffold and reduced rhBMP-7 dose for the regeneration of critical-sized defects in sheep tibiae. Biomaterials. 2013;34(38):9960-8.

91. Aronin CEP, Sefcik LS, Tholpady SS, Tholpady A, Sadik KW, Macdonald TL, et al. FTY720 promotes local microvascular network formation and regeneration of cranial bone defects. Tissue Eng A. 2010;16(6):1801-9.

92. DiGiovanni CW, Lin SS, Baumhauer JF, Daniels T, Younger A, Glazebrook M, et al. Recombinant human platelet-derived growth factor-BB and betatricalcium phosphate (rhPDGF-BB/ $\beta$-TCP): an alternative to autogenous bone graft. JBJS. 2013;95(13):1184-92

93. Cochran DL, Oh T-J, Mills MP, Clem D, McClain P, Schallhorn R, et al. A randomized clinical trial evaluating rh-FGF-2/ $\beta-T C P$ in periodontal defects. J Dent Res. 2016;95(5):523-30.

94. Emam H, Beheiri G, Elsalanty M, Sharawy M. Microcomputed tomographic and histologic analysis of anorganic bone matrix coupled with cell-binding peptide suspended in sodium hyaluronate carrier after sinus augmentation: a clinical study. Int J Oral Maxillofac Implants. 2011;26(3):561-70.

95. Sharma S, Kelly TK, Jones PA. Epigenetics in cancer. Carcinogenesis. 2010; 31(1):27-36

96. Salarinia R, Sahebkar A, Peyvandi M, Reza Mirzaei H, Reza Jaafari M, Matbou Riahi M, et al. Epi-drugs and Epi-miRs: moving beyond current cancer therapies. Curr Cancer Drug Targets. 2016;16(9):773-88.

97. Stegemann R, Buchner DA. Transgenerational inheritance of metabolic disease. Semin Cell Dev Biol. 2015;43:131-40.

98. Ivanov M, Barragan I, Ingelman-Sundberg M. Epigenetic mechanisms of importance for drug treatment. Trends Pharmacol Sci. 2014;35(8):384-96.

99. Kornblith $A B$, Herndon JE, Silverman LR, Demakos EP, Odchimar-Reissig $R$, Holland JF, et al. Impact of azacytidine on the quality of life of patients with myelodysplastic syndrome treated in a randomized phase III trial: a Cancer and Leukemia Group B study. J Clin Oncol. 2002;20(10):2441-52.

100. Issa JP, Garcia-Manero G, Giles FJ, Mannari R, Thomas D, Faderl S, et al. Phase 1 study of low-dose prolonged exposure schedules of the hypomethylating agent 5-aza-2'-deoxycytidine (decitabine) in hematopoietic malignancies. Blood. 2004;103(5):1635-40.

101. Matei D, Fang F, Shen C, Schilder J, Arnold A, Zeng Y, et al. Epigenetic resensitization to platinum in ovarian cancer. Cancer Res. 2012;72(9):2197-205.

102. Heerboth S, Lapinska K, Snyder N, Leary M, Rollinson S, Sarkar S. Use of epigenetic drugs in disease: an overview. Genet Epigenetics. 2014;6:GEG. S12270.

103. Paino F, La Noce M, Tirino V, Naddeo P, Desiderio V, Pirozzi G, et al. Histone deacetylase inhibition with valproic acid downregulates osteocalcin gene expression in human dental pulp stem cells and osteoblasts: evidence for HDAC2 involvement. Stem Cells. 2014;32(1):279-89.

104. Candelaria M, Herrera A, Labardini J, González-Fierro A, Trejo-Becerril C, TajaChayeb $L$, et al. Hydralazine and magnesium valproate as epigenetic treatment for myelodysplastic syndrome. Preliminary results of a phase-II trial. Ann Hematol. 2011;90(4):379-87.

105. Duvic M, Vu J. Vorinostat: a new oral histone deacetylase inhibitor approved for cutaneous T-cell lymphoma. Expert Opin Investig Drugs. 2007;16(7): $1111-20$.

106. Yardley DA, Ismail-Khan RR, Melichar B, Lichinitser M, Munster PN, Klein PM, et al. Randomized phase II, double-blind, placebo-controlled study of exemestane with or without entinostat in postmenopausal women with locally recurrent or metastatic estrogen receptor-positive breast cancer progressing on treatment with a nonsteroidal aromatase inhibitor. J Clin Oncol. 2013;31(17):2128.

107. D'Souza W, Saranath D. Clinical implications of epigenetic regulation in oral cancer. Oral Oncol. 2015;51(12):1061-8.

108. Giri AK, Aittokallio T. DNMT inhibitors increase methylation in the cancer genome. Front Pharmacol. 2019;10:385.

109. Yu Y, Zeng P, Xiong J, Liu Z, Berger SL, Merlino G. Epigenetic drugs can stimulate metastasis through enhanced expression of the pro-metastatic Ezrin gene. PLoS One. 2010;5(9):e12710. 
110. Blumenschein GR, Kies MS, Papadimitrakopoulou VA, Lu C, Kumar AJ, Ricker $J$, et al. Phase II trial of the histone deacetylase inhibitor vorinostat (Zolinza ${ }^{\mathrm{TM}}$, suberoylanilide hydroxamic acid, SAHA) in patients with recurrent and/or metastatic head and neck cancer. Investig New Drugs. 2008;26(1): $81-7$

111. Guo X, Wei J, Gao L, Xing B, Xu Z. Hyperammonemic coma after craniotomy: hepatic encephalopathy from upper gastrointestinal hemorrhage or valproate side effect?: case report and literature review. Medicine. 2017;96(15):e6588.

112. Connolly RM, Rudek MA, Piekarz R. Entinostat: a promising treatment option for patients with advanced breast cancer. Future Oncol. 2017;13(13):1137-48.

113. Li Z, Rana TM. Therapeutic targeting of microRNAs: current status and future challenges. Nat Rev Drug Discov. 2014;13(8):622-38.

114. Eslaminejad MB, Fani N, Shahhoseini M. Epigenetic regulation of osteogenic and chondrogenic differentiation of mesenchymal stem cells in culture. Cell J (Yakhteh). 2013;15(1):1.

115. Chen YS, Wu R, Yang X, Kou S, MacDougald OA, Yu L, et al. Inhibiting DNA methylation switches adipogenesis to osteoblastogenesis by activating Wnt10a. Sci Rep. 2016;6:25283.

116. Lee JY, Lee YM, Kim MJ, Choi JY, et al. Methylation of the mouse Dlx5 and Osx gene promoters regulates cell type-specific gene expression. Mol Cells. 2006;22:182-8.

117. Zhou GS, Zhang XL, Wu JP, Zhang RP, Xiang LX, Dai LC, et al. 5-Azacytidine facilitates osteogenic gene expression and differentiation of mesenchymal stem cells by alteration in DNA methylation. Cytotechnology. 2009;60(1-3):11.

118. Cho HH, Park HT, Kim YJ, Bae YC, Suh KT, Jung JS. Induction of osteogenic differentiation of human mesenchymal stem cells by histone deacetylase inhibitors. J Cell Biochem. 2005;96(3):533-42.

119. La Noce M, Mele L, Laino L, Iolascon G, Pieretti G, Papaccio G, et al. Cytoplasmic interactions between the glucocorticoid receptor and hdac2 regulate osteocalcin expression in vpa-treated MSCs. Cells. 2019;8(3):217.

120. McGee-Lawrence ME, McCleary-Wheeler AL, Secreto FJ, Razidlo DF, Zhang M, Stensgard BA, et al. Suberoylanilide hydroxamic acid (SAHA; vorinostat) causes bone loss by inhibiting immature osteoblasts. Bone. 2011;48(5):1117-26.

121. Xu S, De Veirman K, Evans H, Santini GC, Broek IV, Leleu X, et al. Effect of the HDAC inhibitor vorinostat on the osteogenic differentiation of mesenchymal stem cells in vitro and bone formation in vivo. Acta Pharmacol Sin. 2013;34(5):699-709.

122. Lee $\mathrm{ZH}$, Kim HJ, Ryoo HM. A novel osteogenic activity of suberoylanilide hydroxamic acid is synergized by BMP-2. J Bone Metab. 2015;22(2):51-6.

123. Boer JD, Licht R, Bongers M, Klundert TVD, Arends R, Blitterswijk CV. Inhibition of histone acetylation as a tool in bone tissue engineering. Tissue Eng. 2006;12(10):2927-37.

124. Hu X, Zhang X, Dai L, Zhu J, Jia Z, Wang W, et al. Histone deacetylase inhibitor trichostatin A promotes the osteogenic differentiation of rat adipose-derived stem cells by altering the epigenetic modifications on Runx2 promoter in a BMP signaling-dependent manner. Stem Cells Dev. 2013;22(2):248-55.

125. Hu N, Wang C, Liang X, Yin L, Luo X, Liu B, et al. Inhibition of histone deacetylases potentiates BMP9-induced osteogenic signaling in mouse mesenchymal stem cells. Cell Physiol Biochem. 2013;32(2):486-98.

126. Chen TH, Chen WM, Hsu KH, Kuo CD, Hung SC. Sodium butyrate activates ERK to regulate differentiation of mesenchymal stem cells. Biochem Biophys Res Commun. 2007;355(4):913-8.

127. Hu X, Fu Y, Zhang X, Dai L, Zhu J, Bi Z, et al. Histone deacetylase inhibitor sodium butyrate promotes the osteogenic differentiation of rat adiposederived stem cells. Develop Growth Differ. 2014;56(3):206-13.

128. Ali D, Hamam R, Alfayez M, Kassem M, Aldahmash A, Alajez NM. Epigenetic library screen identifies abexinostat as novel regulator of adipocytic and osteoblastic differentiation of human skeletal (mesenchymal) stem cells. Stem Cells Transl Med. 2016;5(8):1036-47.

129. Jing H, Liao L, An Y, Su X, Liu S, Shuai Y, et al. Suppression of EZH2 prevents the shift of osteoporotic MSC fate to adipocyte and enhances bone formation during osteoporosis. Mol Ther. 2016;24(2):217-29.

130. Dudakovic A, Camilleri ET, Xu F, Riester SM, McGee-Lawrence ME, Bradley EW, et al. Epigenetic control of skeletal development by the histone methyltransferase Ezh2. J Biol Chem. 2015;290(46):27604-17.

131. Khanban H, Fattahi E, Talkhabi M. In vivo administration of G9a inhibitor A366 decreases osteogenic potential of bone marrow-derived mesenchymal stem cells. EXCLI J. 2019;18:300.
132. Fan X, Li L, Ye Z, Zhou Y, Tan WS. Regulation of osteogenesis of human amniotic mesenchymal stem cells by sodium butyrate. Cell Biol Int. 2018; 42(4):457-69.

133. Lee S, Park JR, Seo MS, Roh KH, Park SB, Hwang JW, et al. Histone deacetylase inhibitors decrease proliferation potential and multilineage differentiation capability of human mesenchymal stem cells. Cell Prolif. 2009;42(6):711-20

134. Salami H, Mowal SJ, Moukhah R, Hajebrahimi Z, Hosseini SA, Edalat H. Evaluating the differential effects of valproic acid on Wharton's jelly mesenchymal stem cells. Adv Pharm Bull. 2019;9(3):497.

\section{Publisher's Note}

Springer Nature remains neutral with regard to jurisdictional claims in published maps and institutional affiliations. 